\title{
A Review on Seismic Retrofit of Beam-Column Joints
}

\author{
Sreadha $A R^{1} \mid$ Dr.C.Pany ${ }^{2} \mid M V$ Varkey ${ }^{3}$ \\ ${ }^{1}$ PG Student, Department of Civil Engineering, Amal Jyothi College of Engineering \& Technology, Kanjirapally, India \\ 2 Engineer, VSSC, Trivandrum, Kerala, India \\ ${ }^{3}$ Assistant Professor, Department of Civil Engineering, Amal Jyothi College of Engineering \& Technology,Kanjirapally, \\ India
}

To Cite this Article

Sreadha A R, Dr.C.Pany and M V Varkey, "A Review on Seismic Retrofit of Beam-Column Joints”, International Journal for Modern Trends in Science and Technology, 6(9): 80-93, 2020.

\section{Article Info}

Received on 12-August-2020, Revised on 20-August-2020, Accepted on 27-August-2020, Published on 07-September-2020.

\section{ABSTRACT}

Earthquakes are one of the biggest life-threats in the world. The effect is immediate, with little to no warning about damage plans and the collapse of buildings/structures. Prevention of earthquake-related disasters has become more and more important in recent years. Preventing disasters involves reducing seismic risk by retrofitting existing buildings. Seismic retrofitting has now become a crucial issue. Retrofitting helps improve the structure's strength, resistivity and overall lifespan. Recent occurrences of earthquakes in various parts of the world have clearly shown the urgency of repairing deficient seismic structures. The paper summarised many past studies in the form of a seismic strengthening solution, based on the type of beam-column joints, retrofitting technology and fiber reinforced polymers (FRP).

KEYWORDS: Earthquake, Structures, Retrofitting, Beam-column joint, Fibre reinforced polymer

\section{INTRODUCTION}

Earthquakes damage over the years has happened because of significant structural flaws in some reinforced concrete buildings constructed in the early 1960s. These deficiencies are mainly a consequence of poor structural capacity design approach and/or detailing of reinforcement. Which gives, the lateral strength and ductility of these structures were minimal. The wrapping of reinforced concrete $(\mathrm{RC})$ members with FRP sheets including carbon, glass, or aramid fibers, bonded together in a matrix made of epoxy, vinyl ester, or polyester, has been used extensively throughout the world in numerous retrofit applications in RC buildings. These are alternate strengthening systems to conventional methods, such as steel plate bonding and shotcreting.
The safety threat in the case of an earthquake is almost entirely connected to man-made structures such as buildings, dams, bridges etc. Prevention of disasters caused by the earthquake has become increasingly important in recent years. Prevention of earthquakes means reducing earthquake damage by retrofitting existing structures to meet the seismic protection criteria. The preparation of improvements to existing structures varies from new plans by a significant condition; the existing building must be used as the basis for both planning and construction acts. By adopting proper design methodology and quality control of building, the new structure can be designed adequately earthquake resistant. But the existing old structures that were built largely without considering this important feature, pose a huge seismic risk, particularly to human life and 
historical monuments. Many existing buildings don't meet the criteria of seismic efficiency. For either of the following factors the need for seismic retrofitting of an existing building can arise: (1) building not built for standards (2) no subsequent update of code and construction practices (3) subsequent upgrade of seismic zone (4) weakening of strength and aging (5) alteration of existing structure (6) alteration of building use, etc. Nearly 85 percent of India's total buildings are un-engineered structures that consist of earthen walls, stone walls, brick masonry walls, etc. Many structures are more fragile, and there is likely to be a significant loss of lives and property in the case of a large earthquake. Seismic retrofit is mainly applied to ensure public protection, with economic considerations deciding different levels of construction and material survivability. In recent years, there has been an increasing need to repair weakened structures as part of preventive disaster mitigation and to figure out the improvements that should be made to a built system to enhance structural stability during an earthquake. One of the key factors that restrict seismic performance in existing structural structures constructed according to old code requirements is the occurrence of brittle failure in RC buildings. This is attributed to the shortage of joint transverse repairs typically seen in existing $\mathrm{RC}$ buildings worldwide prior to the 1970s. Indeed, the lack of widely accepted theories and formulations of the joint capacity resulted in many years in these joints being completely overlooked in design and construction practice. Because in many countries the largest development of civil infrastructure took place prior to the 1970 s, many structures are susceptible to joint failure under seismic loading. Because of the relevance of joint failure in overall building performance, current research efforts have focused on developing sound, cost-effective retrofit strategies, and techniques for old-style beam-column joints. Different seismic retrofitting schemes such as providing external post-tensioning, providing infill shear wall, providing additional brazing's, providing steel plates at tension zones of beams, etc are available. Apart from all these retrofitting schemes, FRP has a major advantage i.e. high strength to low weight ratio, this unique feature of FRP material made it as a common retrofitting material. Widespread use of fiber-reinforced cement (FRC) composites and high-performance fiber-reinforced cement composites (HPFRCC) has opened new frontiers in the nature of RC members' sheer ability. The high tensile strength, durability, and damage resistance make these materials desirable for use in earthquake-resistant structures, with emphasis on shear-dominated response RC members. While the use of fiber-reinforced concrete has become standard practice for modern structural systems, only a few studies have concentrated on the use of HPFRCC materials for the seismic reconstruction of existing structural systems. Rehabilitation using FRP composites provides benefits such as simple and fast assembly, a high strength/weight ratio, and corrosion resistance. Rehabilitation of $\mathrm{RC}$ beam-column joints has been tested using FRP jackets to enhance joint shear strength.

For building structures, the seismic failure mechanisms have two types, the local and the global failure mechanism, as shown in Fig. 1 and Fig 2. Frame-supported structure or soft storey structure, block structure, are the structural forms that are vulnerable to local failure. Ductile frame, shear wall structure, tube structure, cluster tube structure, and mega frame structures are the types of structure to form global failure.
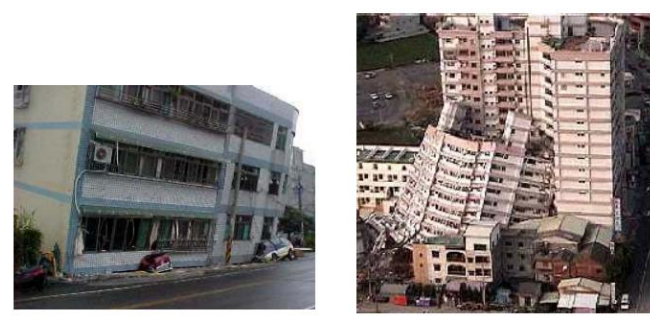

Fig 1: Local failure mechanism [1]

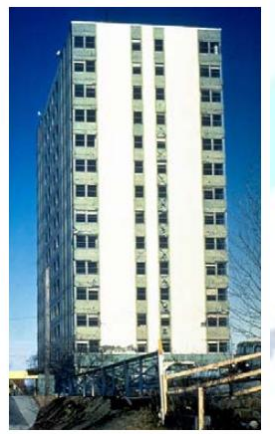

Fig 2: Global failure mechanism [1]

\section{Failure of structure - Examples}

\section{- 1985 Mexican earthquake[2]}

On September 19, 1985, an 8.1 magnitude earthquake took place off the Mexican Pacific coast between Jalisco and Oaxaca (Fig 3). A structure on soft soil subjected to severe ground motion will have its fundamental period lengthened as a result of both foundation rocking rotations and structural 
damage. Foundation rocking increases the duration of vibration of the structure, increases the contribution-from higher modes of vibration, and results in greater forces in the upper floors. These effects have resulted in damage to the middle and upper floors of several buildings. The characteristics of the motion of the ground, the torsional eccentricities, the contribution of the base rocking on the soft soil, and possibly the friction between the wings, probably all contributed to the failure.

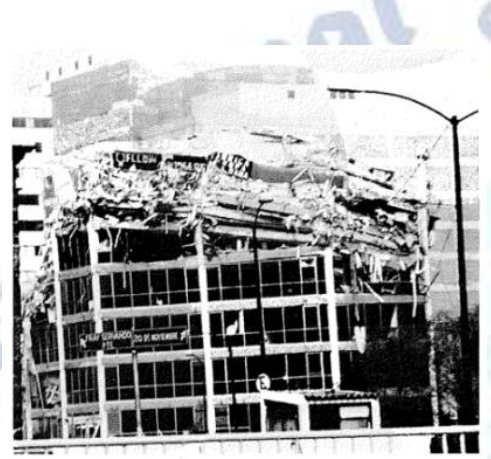

Fig 3: Collapse of upper storeys [2]

\section{- 1989 Loma Prieta earthquake[3]}

An earthquake of magnitude 7.1 occurred on 17 October 1989 at Pacific daylight time in northeast Santa Cruz, California (Fig 4). This earthquake has caused significant extensive damage to buildings and bridges in the Greater San Francisco Bay area. In addition to the low seismic force levels of construction, the major contributing factors resulting in significant damage or failure were: 1) loss of support for the superstructure due to large longitudinal movements or lack of control over supports. 2) Extreme settlement of support and approach slabs due to the presence of soft soil or filling. 3) Poor detailing of column tie reinforcement in bridge piers, including excessive tie spacing's and inadequate anchorage of the free ends of the ties. 4) Inadequate anchorage of longitudinal column reinforcement into foundations as well as into the superstructure, resulting in pull-out reinforcement failures at those sites.
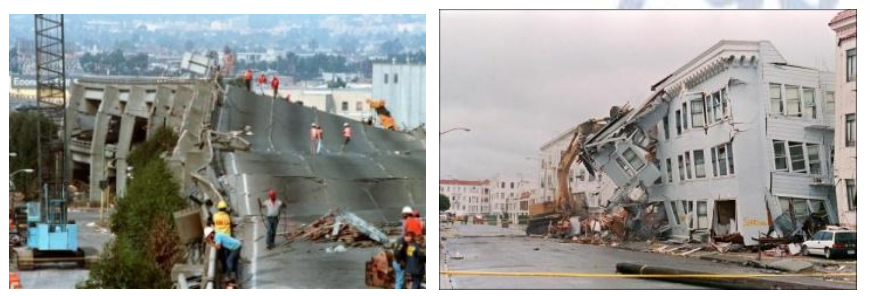

Fig 4: Collapse of bridge and building [Los Angeles Times]

\section{- 1994 Northridge earthquake[4]}

An earthquake of magnitude 6.8 damaged a variety of structures on January 17, 1994, in Northridge (Fig 5). It should be noted that many of the structures damaged during the 1994 Northridge earthquake were older structures that were designed using earlier codes. While the damage from this earthquake illustrated the importance of proper design and detailing to achieve ductile responses of concrete structures. These include the following: (1) Most of the reinforced concrete structures that were damaged were older, non-ductile structures. (2) Precast concrete structures must have adequate connections between beams and columns and adequate load paths must be provided for lateral forces through floor and roof diaphragms. (3) The 1994 Northridge earthquake provided evidence that the ductile frame members were appropriate. (4) The earthquake damage clearly demonstrated the known deficiencies in older tilt-up structures due to inadequate connections between the floor and roof diaphragms and the tilt-up wall panels.

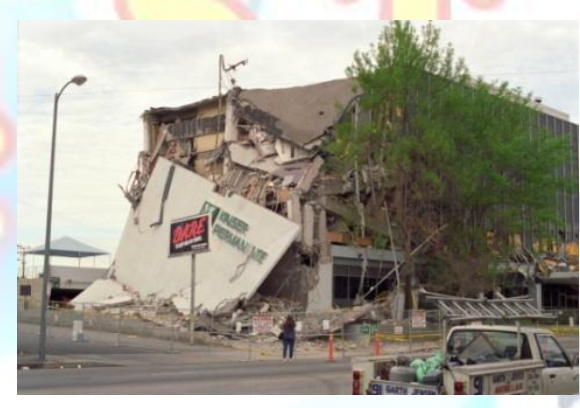

\section{Fig 5: Partial collapse of the building [magazine.ucla.edu]}

\section{- 1999, Kocaeli (Turkey) earthquake [5]}

On August 17, 1999, an earthquake of magnitude 7.4 occurred along the North Anatolian Fault (Fig 6). The main reasons for the collapse are the following: (i) The presence of partial height masonry infills led to failure in some columns at the level of the top of the damaged infills where the columns contained splices of the vertical bars. (ii) Connection failures like cantilever - column, cantilever - beam, and beam-stringers connection. (iii) Site visiting teams from many countries, including experts in Turkey, generally recognise that the primary factor leading to poor structural performance was the inadequate and sometimes non-existent regulatory enforcement of both design and construction. 

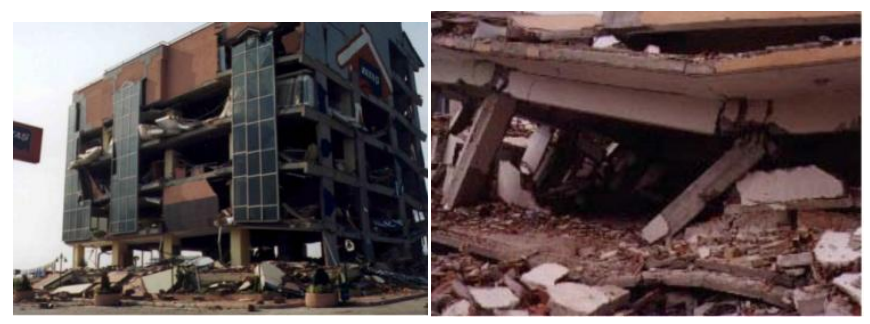

Fig 6: Collapse of building [5]

\section{OVERVIEW OF SEISMIC RETROFIT OF REAL BEAMCOLUMN JOINTS}

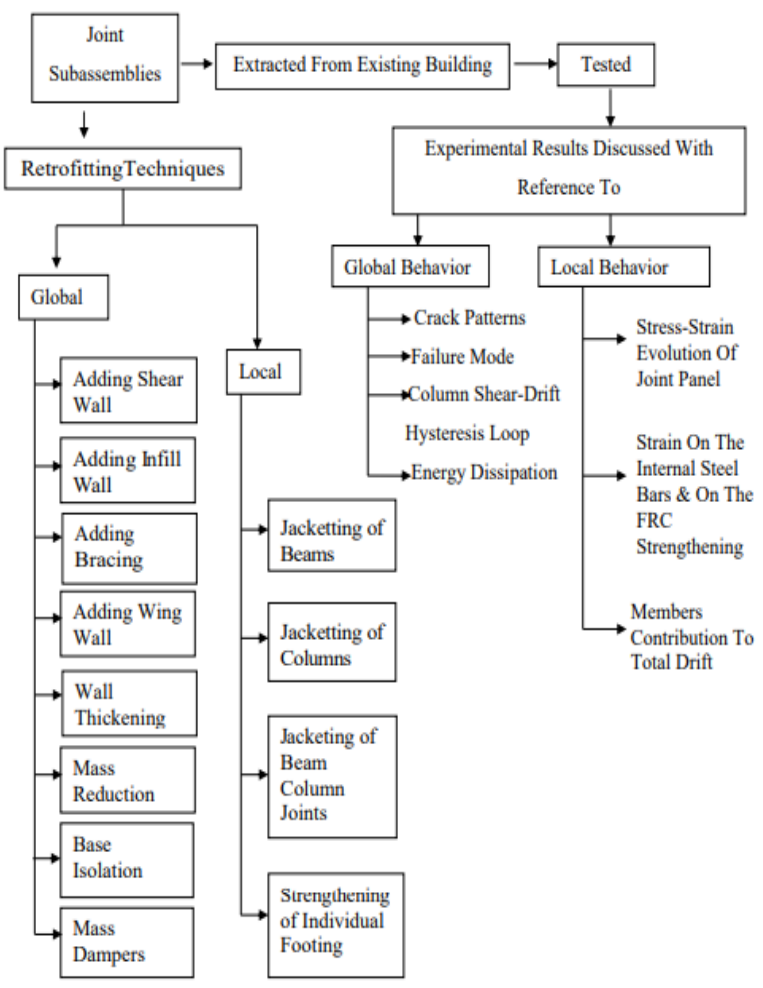

\section{TECHNIQUES OF RETROFITTING}

The decision to strengthen the structure before the occurrence of an earthquake depends on the seismic resistance of the building. The structural system of the deficient building should be sufficiently reinforced to obtain the required degree of seismic resistance. The term reinforcement includes technical interventions in a building's structural system which improve its seismic resistance by increasing strength, rigidity, and/or ductility. A reinforcement scheme consists of one / many reinforcing techniques to remedy the structural defect. Such schemes are specific to the structural system and material type. Minakshi V. Vaghani et al. [6] and Komal Bedi [7] gives a description of major techniques that are used for reinforced concrete buildings. An example fig showing before and after retrofitting technique is shown in Fig 7. Depending on the various forms and structural conditions various seismic retrofit techniques are available.

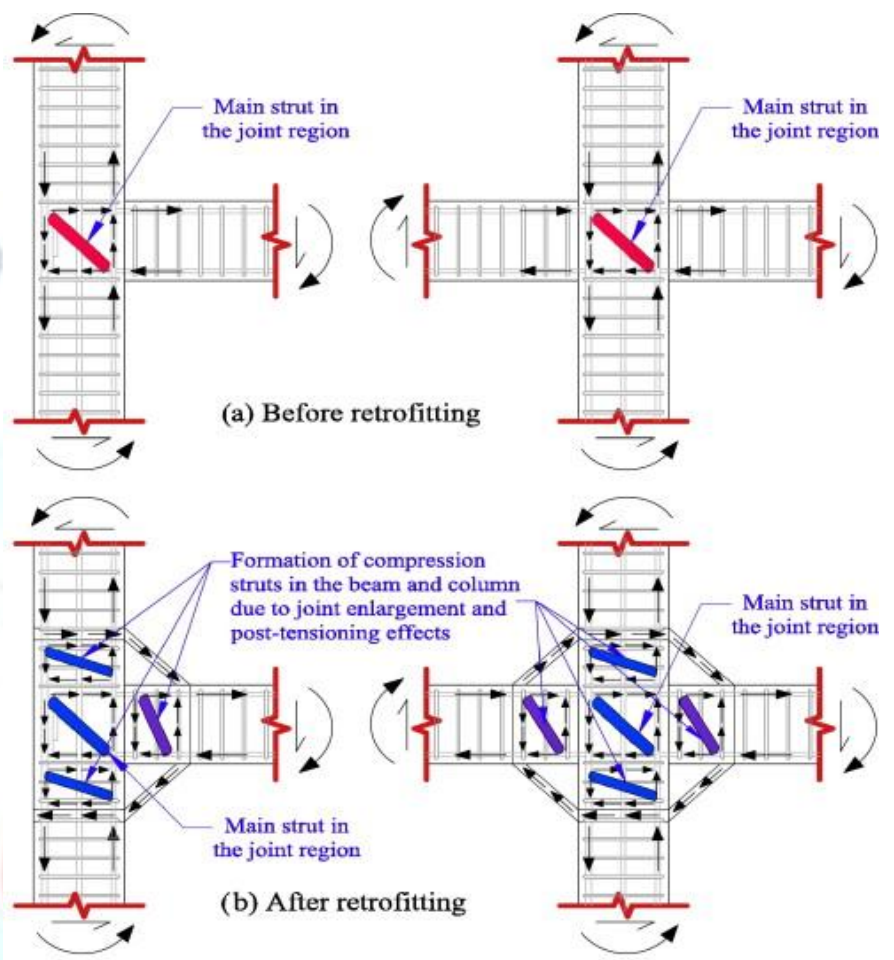

External beam-column joint

Internal beam-column joint

\section{Fig 7: Beam-column joint before and after retrofitting [8]}

\section{- Jacketing}

For the column, jacketing is excellent but may not be too effective for beam or slab. It is possible to jacket existing beams, columns, or joints with new overlays in reinforced concrete, steel, or fibre wrap. The new materials are to be designed and constructed for composite action with the existing concrete. Where reinforced concrete jackets are used, details to improve ductility shall be provided in the design. Retrofitting of the columns is often critical to a structure's seismic performance. During earthquakes, columns can never be the weakest elements of the building structure to prevent the mechanism of the storey. In a building structure a column's response is influenced by its axial load, flexure, and shear combined. Column jacketing can therefore be used to increase column shear and flexural strength so that the columns do not get damaged. For jacketing, fibre-reinforced composite (FRC) material is used during retrofitting of columns. 


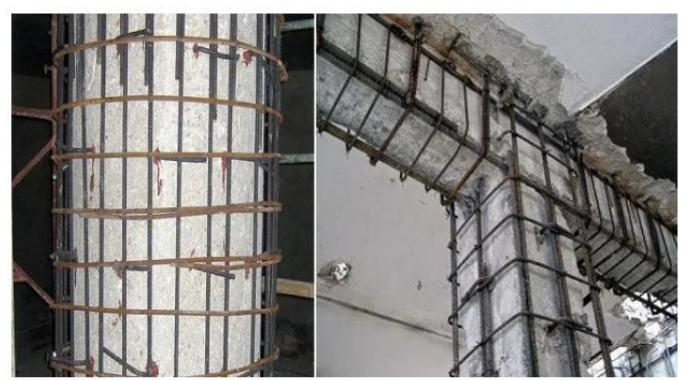

Fig 8: Concrete column beams strengthening [theconstructor.org]

\section{- FRP Strengthening}

A fibre-reinforced polymer (FRP) is usually made up of high tensile continuous fibres directed in the desired direction in a specialised resin matrix. These continuous fibres are bonded to the member's outer surface to be reinforced in the direction of the tensile force or as a normal confining reinforcement to its axis. FRP may improve the deficient member's shear, flexural, compressive capacity, and ductility. The most common types of fibres used in most commercially available FRPs are glass fibres. In structural applications FRP systems are typically used. FRP reinforcement is a fast, smooth, effective and aesthetically pleasing technique for rehabilitating reinforced concrete structures with pre-stressed concrete. FRP systems have high physical and chemical deterioration or mechanical actions as opposed to steel plates.

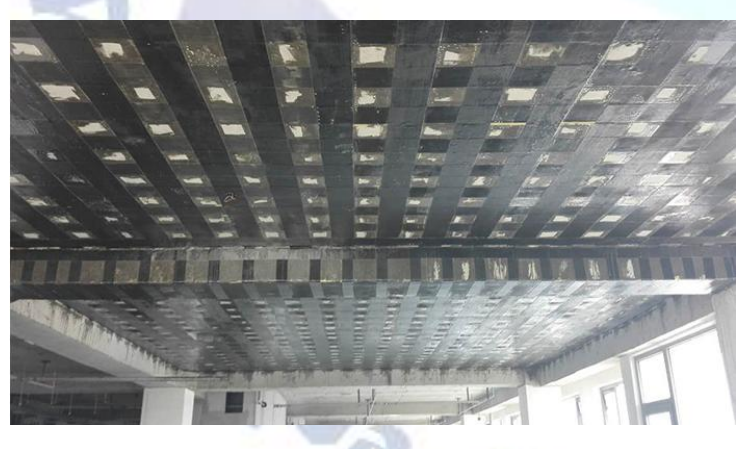

Fig 9: Strengthening by fibre reinforced polymer (FRP) wrap [www.horseen.com]

\section{- Friction Damper}

Usually, friction damper is part of a steel brace structure placed within a column-beam frame, composed of specially coated steel sheets which are attached together. The commonly used friction damper systems are created by the $\mathrm{X}$ (friction damper in the centre of the $\mathrm{X}$ ) within the rectangular column-beam structure. or a diagonal (friction damper is around the diagonal). At the column-beam joints such a friction damper mechanism is connected to the structural frame by means of connectors. The role of the friction damper system is identical to that of an automotive shock absorption device. Earthquakes release energy through ground shaking movements, which cause seismic loads to a system of buildings. Friction dampers absorb the energy (or load) induced by the earthquake when the steel plates move at a fixed slip speed toward each other, i.e. dissipate the energy caused by the earthquake by friction-generated heat energy. The installation of friction dampers to an existing building increases the seismic load-bearing capacity of the building structure by reducing the building's need for seismic resistance on existing load-bearing components.

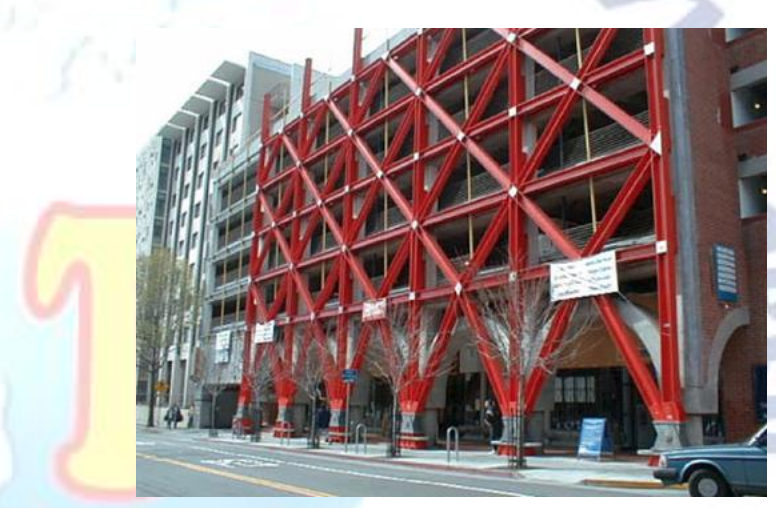

Fig 10: Installation of Friction Damper [www.sensequake.com]

\section{- Ferrocement}

Ferrocement consists of multiple layers of fine rod hardware mesh with a 3-8 percent protection ratio completely protected by a high strength (15-30 $\mathrm{MPa}$ ) cement mortar base (10-50 $\mathrm{mm}$ thick). The mortar with a coating thickness of $1-5 \mathrm{~mm}$ is trowled on through the wire. The ferrocement's mechanical properties depend on the mesh properties. Since it is inexpensive and can be achieved with unskilled labour, ferrocement is suitable for low cost housing. The mesh helps confining the masonry units after cracking and thereby increases the potential for inelastic deformation in the wall.

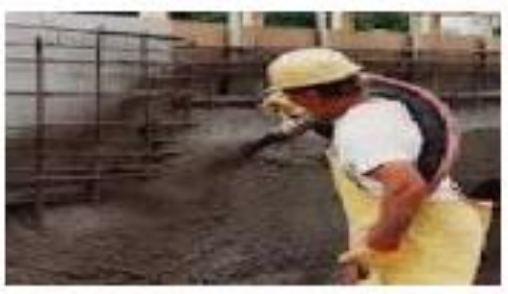

Fig 11: Ferrocement techique [6] 


\section{- Base Isolators}

Base isolation is typically ideal for low to medium-rise structures, normally up to 10-12 floors high, with their specific frequencies within the range of predicted dominant earthquake frequencies. In evaluating the applicability and effectiveness of seismic isolation, superstructure characteristics such as height, width, aspect ratio and rigidity are important. The region's seismicity and the soil conditions underlying it should also be considered in feasibility studies and design phase. The restriction in applying base isolation is the large relative displacements at the insulation level between the superstructure and the supporting field. To withstand the expected large displacements, clearance around the building must be given and preserved over the life of the construction. Through the introduction of increased stiffness and energy dissipation processes in the insulation system, such displacements may be minimised. Insulators have low horizontal rigidity and are mounted between the base and the frame.

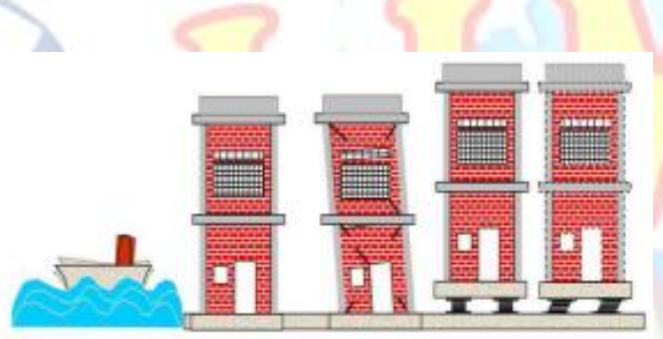

Fig 12: Principles of Base Isolation Technology [7]

\section{- Grout and Epoxy Injection}

Grout injection is a common technique of strengthening, as it does not change the aesthetic and architectural characteristics of the existing buildings. The key aim of injections is to preserve the original integrity of the retrofitted wall and to fill the voids and cracks present in the masonry due to slab will prevent shear failures from punching.
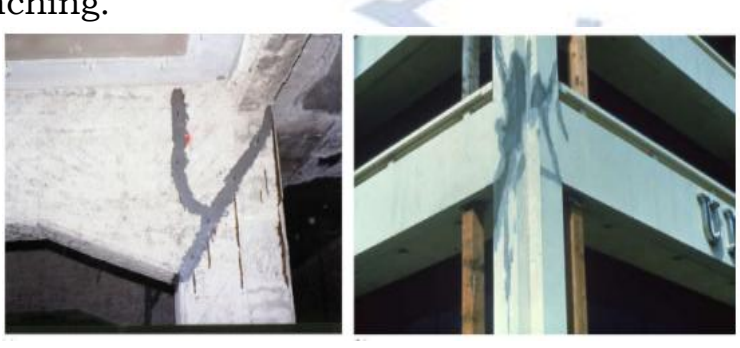

Fig 13: Application of the epoxy resin \& cement grout injection in beam-column joint [9]

\section{LITERATURE REVIEW}

C. Del Vecchio et al. [10] studied the seismic behaviour of old-style reinforced concrete beam-column joints and the application of fibre-reinforced concrete (FRC) as a seismic strengthening solution. For this analysis, a five-story RC building was chosen that was destroyed by the L'Aquila earthquake. A detailed seismic assessment and design of retrofit alternatives carried out during the reconstruction process. Also, experimental testing of structural members extracted from existing structural systems. The experimental results are discussed w.r.t global behaviour $\&$ local behaviour. The joint tested in the as-built configuration shows brittle failure with joint diagonal cracking, as commonly observed in the aftermath of recent devastating earthquakes. The thin FRC jacketing avoids shear failure of the joint plate, supporting a more desirable yield of beams. The strengthening system avoided joint panel shear failure, promoting more-ductile beam yielding in both the directions. This resulted in a significant increase in term of shear strength and energy dissipation compared with the control specimen. Abdelhak Bousselham [11] carried out a comprehensive synthesis of experimental investigations performed on the use of FRP for the seismic retrofit of RC building joints and develop a simple design method for the calculation of the FRP contribution to the shear strength of beam-column joints externally retrofitted with FRP. The review of these studies shows that the FRP strengthening technique is a promising alternative to traditional techniques. Reported test results indicate the substantial enhancements due to FRP in terms of strength, ductility \& energy dissipation of joint cores. Furthermore, the paper provides a basic model of design for estimating the FRP's contribution to the shear ability of exterior joints. Costas P. Antonopoulos et al. [12] have done an experiment to know the behaviour of shear-critical exterior reinforced concrete $\mathrm{RC}$ joints strengthened with fibre-reinforced polymers FRP under simulated seismic load. The tests performed in this study demonstrated that externally bonded FRP reinforcement is a viable solution towards enhancing the strength, energy dissipation, and stiffness characteristics of poorly detailed in shear $\mathrm{RC}$ joints subjected to simulated seismic loads. Chris P. Pantelides et al. [13] determine the strengthening of $\mathrm{RC}$ beam-column interior joints in building frames which are deficient under seismic 
loads are addressed using carbon FRP composite jackets. The test results show that CFRP jackets are an effective rehabilitation measure to enhance the seismic performance of existing beam-column joints with insufficient seismic information in terms of increased joint shear strength and inelastic rotation capability. Also, CFRP laminates are effective rehabilitation measures for overcoming problems associated with beam bottom steel bars that have inadequate embedment into the beam-column joints. The rehabilitation measures achieved a relatively greater improvement of the performance for shear deficient specimens. Halil Sezen [14] has done a study to restore the strength and improve the deformation capacity of the damaged beam-column joints, to change the failure mode from shear failure in the joint region to more ductile flexural failure in the beam, to prevent or delay bulging and debonding of FRP wrap under large loads, and provide effective anchorage for the FRP strips. Samples were subjected to quasi-static reversed cyclic loading. The repair and strengthening method almost restored the strength of the two beam-column joint specimens and increased the deformation capacity in all specimens. Diagonal FRP strips were very effective in increasing the shear resistance of the joint region. Ductile beam failures were less common primarily because of the debonding of FRP sheets from the concrete surface or inadequate anchorage of FRP sheets. Ciro Del Vecchio et al. [15] investigates the reliability of available capacity models to predict the strength and deformability of unconfined beam-column joints. The experimental program involved six tests on as-built and retrofitted beam-column specimens. Of the total number of six subassemblies, three specimens were tested in the as-built configuration. Three specimens were strengthened to investigate the benefits provided by different FRP layouts. Experimental testing on FRP-strengthened specimens showed that the suggested reinforcement solutions for seismic retrofitting of poorly designed RC beam-column joints are successful. Bing Li et al. [16] presents the seismic behaviour of three typically as-built non seismically RC beam-column joints subjected to constant axial compression load and reversed cyclic loading simulating low to moderate earthquake forces and also examines the strengthening schemes through the experimental studies. Design six non-seismically accurate, full-scale, interior beam-column joints, and tested. From the results of the experimental program, effective and economical FRP strengthening schemes are developed for existing non seismically detailed interior $\mathrm{RC}$ beam-column joints. A comparison between the performance of original specimens and strengthened ones shows a tremendous increase in strength, stiffness, and energy dissipation capacity. Gao $\mathrm{Ma}$ et al. [17] proposed a seismic retrofit design method using FRP for the beam-column joints damaged RC frame structures and to validate this method through shake table tests. The damaged structure was retrofitted using epoxy injection and Basalt fiber-reinforced polymer sheets and re-tested. The following conclusions can be drawn: For the frame structure with severely damaged beam-column joints after the earthquake loading, the seismic capacity of the structure was restored and significantly improved through epoxy injection and FRP retrofitting. After epoxy injection and retrofitting with FRP, each storey's effective stiffness was significantly improved. The FRP-retrofitted structure exhibited greater ductility and energy dissipation capacity than before retrofitting. No debonding between the FRP sheets and the joints was observed after the shake table tests. The original weak beam-column joint failure mode was prevented by the FRP retrofitting. Umut Akguzel et al. [18] demonstrated the results of differing axial and bidirectional loading on seismic efficiency of defective external RC beam-column joints before and after retrofitting. A total of ten exterior beam-column joint subassemblies were tested under quasi-static cyclic loading, including four as-built specimens and six retrofitted specimens using externally bonded glass FRP (GFRP) sheets. The test results confirmed that a combination of biaxial loading with a high concurrent varying axial load on the corner joints can, in fact, lead to a severe reduction in deformation and strength capacity in the as-built specimen. Stefano Pampanin et al.[19] Presented feasibility and reliability of seismic retrofit activity using externally bonded fibre-reinforced polymer composites on existing reinforced concrete frame structures, developed prior to the implementation of existing accepted seismic construction code requirements, focused on theoretical and experimental studies of beam-column joint subassemblies and frame systems. The experimental program on existing (as-built) RC frame subassemblies and systems comprised of quasi-static tests on six, one-way beam-column joint subassemblies as well as on a three-storey three-bay frame system. The experimental results 
of quasi-static tests on beam-column joint specimens and three storey frame systems and retrofitted with CFRP laminates provided very satisfactory confirmation of the efficiency of similar solutions for existing poorly detailed buildings. Amir Mirmiran et al. [20] established a structure for a better understanding of the behaviour of concrete columns covered in fibre-wrapped or FRP using uniaxial compression tests. A total of thirty cylindrical specimens were tested, which included 24 concrete-filled FRP tubes and six plain concrete specimens. Uniaxial compression experiments on concrete-filled FRP tubes show that fibre composites are an important form of confinement, as they improve the strength and ductility of concrete considerably. Gia Toai Truong et al. [21] proposed various practical rehabilitation solutions using internally embedded head rebars, carbon fibre reinforced polymer (CFRP) wrapping, steel haunch elements, and steel jacketing. To perform testing of the beam-column connections subject to cyclic lateral loading, a strong three-dimensional steel frame was assembled. The retrofit solutions applied in this test were head rebars anchoring, CFRPs wrapping, haunch elements, and steel jacketing. The retrofit methods developed in this study could partially enhance the strength and deformation capacity of the beam-column joints. The test findings showed that the suggested retrofit solutions could partly improve the seismic ability of the beam-column joints: steel jackets could improve deformation and load-carrying power; steel haunch components could increase the load-carrying capacity, stiffness and dissipated energy; and head re-bar anchoring and CFRP wrapping did not greatly impact the seismic performance. A.Ghobarah et al. [22] presented an advanced and practical seismic recovery method for beam-column joints using fibre-reinforced polymers (FRP). A reinforced concrete beam-column joint has been designed and tested. An effective method for repairing existing deficient beam-column joints is presented and a design methodology is outlined. A comparison between the performance of the original specimen and the repaired one shows that the GERP jacket was capable of increasing the shear resistance of the joint and enhancing the performance of the connection from ductility point of view. The FRP can be designed to prevent the brittle joint failure due to shear and allow a plastic hinge to develop in the beam. IdrisBedirhanoglu et al.[23] investigated the seismic behaviour of deficient reinforced concrete exterior beam-column joints constructed with low-strength concrete and plain reinforcing bars before and after retrofitting with prefabricated HPFRCC (high performance fibre-reinforced cementitious composite) panels. The Experiments done for the study are Diagonal tension tests \& Beam-column slab transverse beam sub-assemblage tests. The experimental findings obtained from the diagonal tension experiments and the reversed cyclic joint sub-assembly experiments clearly showed that the HPFRCC panels bonded and bolted to the outer faces of the defective external joints greatly improved the joint shear strength. Xiuling Li et al. [24] created an inexpensive and easy-to-use repair method for $\mathrm{RC}$ columns weakened by the earthquake. Four RC columns were cast and tested to a predetermined damage state under cyclic loads, repaired with HPFRCCs, and tested again. With the progression of damage, the secant stiffness of original and repaired $\mathrm{RC}$ columns degraded rapidly at the beginning and gradually afterwards. The repairing technique can fully recover the initial stiffness of damaged columns while inelastic range. Repairing with the axial load in place can increase the energy dissipation of damaged columns by at least $18 \%$ more than that of the columns repaired with no axial load. Alexander G. Tsonos [25] presents an experimental study to evaluate retrofit methods which address particular weaknesses that are often found in RCC, especially older structures, namely the lack of sufficient flexural and shear reinforcement within the columns and the lack of adequate shear reinforcement within the joints. The effectiveness of the two jacket types was also compared in this article. The reinforced concrete jacket tends to be more efficient in the post-earthquake retrofitting of columns and b / c joints than the high-strength fibre jacket, whereas the reinforced concrete jacket and the high-strength fibre jacket tend to be similarly effective in the case of pre-earthquake reconstruction. In all cases, the observed capacity was predicted to within approximately $10 \%$ of that computed using the joint shear strength formulation. Alireza Zabihi et al. [26] primary formulations for the implementation of a single diagonal haunch were obtained, as well as the generalisation of formulations for all three systems: a non-refitted subassembly, a double haunch retrofitting system and a single haunch retrofitting process. The formulations were then tested for non-retrofitting subassembly and double haunch retrofitting structures using accessible experimental evidence. Finally, through a 
parametric analysis, the performance of the single haunch retrofitting system is compared with that of the double haunch retrofitting system. From this analysis, it is seen that the seismic activity of a poorly designed external beam-column joint can be enhanced by adding a single diagonal haunch, which is a less invasive seismic retrofitting technique that is architecturally more desirable. C. Beschi et al. [27] presents experimental findings on full-scale corner beam-column joints with the aim of evaluating the effectiveness of reinforcing existing RC structures for HPFRC jacket use. The experimental findings demonstrated the seismic instability of corner beam-column joints, built with specifics characteristic of the '60s-'70s Italian building tradition. The experimental findings have indicated an improvement in the seismic efficiency of retrofitted specimens with an HPFRC jacket as compared with unretrofitted ones. The findings illustrate the considerable weakness of the joint panel area and the critical function of the slippage phenomenon due to the use of smooth bars and demonstrate that it is possible to improve the bearing flexibility of the columns with the application of an HPFRC jacket, even achieving an acceptable degree of ductility and strength of the beam-column joints. J. Premalatha et al. [28] carried out FEM modelling to study seismic retrofitting of a reinforced concrete Beam-column joint using. Using the ANSYS Workbench, jacketing methods such as carbon fibre reinforced polymer sheets (CFRP), glass fibre reinforced polymer wire, sisal fibres and crossed bars are done. The wrapping of the beam-column joint was done by a single, double, triple layer of CFRP, GFRP and Sisal fibres with different thickness. This report discusses the efficiency of the retrofitted column beam joint and has been compared to the standard test. Significant increase in strength was observed with increase in the thickness of the FRP sheets. When compared with the conventional beam-column joint, its stiffness was increased by providing CFRP wrapping. Maria Teresa De Risi et al. [29] done experiments to demonstrate the effectiveness of FRP materials for the seismic strengthening of deficient reinforced concrete (RC) beam-column joints. Analyzes the effects of three tests on full-scale, poorly designed RC beam-column joints with a solid column-weak beam hierarchy measured in configurations as-built and FRP-strengthened. Two strengthening solutions that use FRP systems in a light strengthening layout are proposed as a way to increase joint panel shear strength. The proposed
FRP-strengthening solutions did not change the initial stiffness of the joint subassembly. This makes them suitable for application in a local strengthening strategy. The experiments had positive results regarding the performance of the proposed light reinforcement solution in relation to the joint panel sharpening when applied to solid column-weak beam subassemblies. A. Torabi et al. [30] done repair and retrofit of damaged RC beam-column joint with stiffened steel plates. The retrofitting method is based on joint enlargement using stiffened steel plate jacketing of the joint. Under lateral cyclic loading a full-scale external RC beam-column joint was constructed and tested for failure. The damaged joint was subsequently repaired and retrofitted with stiffened steel plate jacket and re-tested under the same cyclic loading protocol as the original joint. The proposed repair and retrofit technique successfully relocated the plastic hinge further into the beam and away from the original damaged plastic hinge region. Use of stiffened steel plate jacketing increases joint capacity by large amounts. The ductility capacity of the joint decreased due to the proposed retrofitting technique. The stiffened steel plate jacketing increased the stiffness of the retrofitted joint compared to the original joint. Yousef A. Al-Salloum et al. [31] studied the performance and effectiveness of carbon fibre-reinforced polymers (CFRP) in the improvement of shear strength and ductility of seismically deficient beam-column joints. Designed four reinforced concrete interior beam-column sub-assemblies with non-optimal configuration specifications. In improving the joint the impact of two separate rehabilitation schemes was examined. CFRP sheets in the first scheme were bonded to the pin, plates, and part of the column regions by epoxy. However, in the second scheme sheets were only bonded to the joint region by epoxy but were essentially protected by mechanical anchorages against any possible debonding. Scheme 1 was noted to be a successful scheme since it strengthens both the joint and the beam. Strengthening a joint and its adjacent members with CFRP sheets at one position can significantly increase the joint's shear strength and ductility but at the same time may also shift the joint's failure mode to the adjacent member. Yousef A. Al-Salloum et al. [32] compares the efficiency and effectiveness of carbon- fibre- reinforced polymer (CFRP) sheets for upgrading the shear strength and ductility of a seismically deficient exterior beam-column joint with American Concrete Institute (ACI)-based design joint 
specimen. Conclusions drawn are externally bonded CFRP sheets which can effectively increase the shear strength as well as the deformation ability of seismically deficient beam-column joints to a degree comparable to the structural joint dependent on ACI. It is possible for CFRP upgraded specimens to exceed the ACI-based beam-column joint ultimate load value with the use of more layers. The use of CFRP sheets can increase the energy dissipation ability of an as-built exterior joint many folds. Because providing joint shear reinforcement at the construction stage is a more economical option than wrapping CFRP sheets at a post-construction stage, it is always desirable to provide adequate shear reinforcement in the joint region. Thendral sundararasan et al. [34] deals with the strengthening of existing buildings using local and global systems. In the global scheme, the addition of the shear wall to the building is one of the most favoured techniques. The shear walls help in increasing the lateral strength of the structure. The failure of the shear wall can be minimized through the usage of FRP materials. Flexural and shear strength can be improved by the use of FRP sheets in horizontal and vertical directions. The CFRP sheets would increase the pre-cracked stiffness, the cracking load and the ultimate flexural capacity of RC walls. The FRP sheets are wrapped around the possible place of shear failure including wall junction and footing. This makes the $\mathrm{RC}$ wall to gain enough shear strength and increase the ductility capacity of the RC wall. Another approach is to use strands of FRP. The FRP Materials are ideal for structures in both RC and Masonry. In the local method, FRP materials are used by the jacketing process to strengthen the column and beam. The weak points, such as beam-column joints, are reinforced by the method of jacketing. Chris G. Karayannis et al.[35] Present findings of an experimental investigation on the behaviour of critical exterior beam joints fixed or strengthened with a mixture of epoxy resin injections and carbon fibre-reinforced plastics (CFRP) sheets and important and practical conclusions to be drawn. The experimental design comprises 12 subassemblies evaluated in cyclic loading for external beam-column joint connection. From the observed responses of the tested specimens, it can be deduced that the epoxy resin injection technique is appropriate for the full restoration of the seismic ability of the joints, as no damage has been observed in the joint area of the specimens after the repair. The combination of this strategy with the use of C-FRP sheets results in a major increase in loading ability, energy absorption and ductility and eventually leads to an increase in the form of damage relative to the specimen's damage modes during the initial loading. Vui Van Cao et al. [36] proposes an FRP retrofitting method, under which FRP is applied uniformly on the basis of the distribution of seismic risk under systems defined by both quantitative and qualitative parameters, is simple yet rather effective at simultaneously minimising seismic damage, the amount of FRP to be used and the installation time. For the considered cases of high - rise buildings to mid-rise non-ductile building systems, the FRP volume decreased by about 31 per cent relative to cases where FRP was distributed equally, resulting in lower construction costs to lower interruption time. Interestingly, while 31 per cent of FRP was saved, the FRP retrofitted frame loss indices were slightly smaller than those in cases of similar FRP distribution, as FRP better served critical locations. The suggested FRP retrofitting solution may be useful for engineering practise because of its flexibility and technical/economical effectiveness. Alper Ilki et al. [37] investigated the seismic performance of reinforced concrete columns constructed with low quality of concrete and insufficient transverse reinforcement before and after retrofitting. Totally twenty almost full-sized specimens have been tested under continuous axial load with a rectangular cross-section and reversed cyclic lateral loads. Both pre-damaged and undamaged columns with these defects have been retrofitted with composite FRP jackets or prefabricated HPFRCC (high-performance cementitious composite reinforced fibre) panels. The test results showed that all reference specimens, which were not retrofitted, failed either due to buckling of longitudinal reinforcement or bond failure with a premature performance loss, whereas retrofitted specimens showed significantly higher performance, especially in terms of ductility. Mahmoud R. Maheri et al. [38] presented a flange-bonded scheme to eliminate plastic hinges from the joint and equate its performance with the web-bonded scheme. For the first time, nonlinear pushover analyses of retrofitted joints of a standard RC frame are conducted and the optimum thicknesses of the FRP sheets are calculated for relocating the plastic hinges. Then the effects of pushover analyses on the joints are used to construct a model reflecting the RC system. To test such seismic performance parameters as ductility, behaviour factor and performance points in relation to a given demand earthquake for each 
unit, more nonlinear pushover analyses are conducted on the retrofitted and the original frames. Flange-bonded FRP laminates greatly improve the moment flexibility and ductility of an $\mathrm{RC}$ beam-column joint Retrofitting the joints of an $\mathrm{RC}$ frame at flanges by FRP laminates will effectively turn a weak column-strong beam frame into a solid beam-strong column frame by relocating the plastic hinges. FRP retrofitting joints at flanges significantly improves the frame's seismic efficiency point. Reyes Garcia et al. [39] carried out shake table test with inadequate beam-column joint detailing in a two-storey RC structure. The frame was fixed and re-tested using carbon fibre reinforced materials (CFRPs) following the initial tests that damaged the foundation.This paper analytically examine the reinforcing technique's usefulness in enhancing the seismic activity of this frame structure. Models of steel concrete bond-slip and bond-strength loss under cyclic load are known to model deficient beam-column joints. The empirical models are used to test the CFRP rehabilitation effectiveness using a series of medium to strong seismic records. The CFRP reinforcement action improved the behaviour of the substandard beam-column joints and resulted in a major increase in the seismic efficiency of the damaged RC structure. It is seen that the affected building will suffer an estimated 65 per cent less global damage compared to the initial structure after the CFRP action if it was exposed to actual excitations from the earthquake. T. El-Amoury et al. [40] proposed techniques for reinforced concrete beam-column joints improvements. Glass fibre-reinforced polymer (GFRP) sheets are wrapped around the joint to avoid loss of the joint shear. To cover the inadequately secured steel beams, GFRP sheets are fastened to the bottom beam face. Three beam-column joints are examined, including a specimen for monitoring and two specimens for recovery. Under a quasi-static load the specimens are tested for failure. The control experiment exhibited mixed modes of brittle joint shear and bond failure, while the rehabilitated specimens displayed a more ductile mode of failure. Comparison between the control and the rehabilitated samples underlined the efficiency of the rehabilitation systems. The joint reconstruction removed the brittle joint shear failure, strengthened the bond conditions of the top beam reinforcement, delayed the slippage of the bottom steel bars, increased the specimen's dissipated energy and minimised the joint's stiffness degradation. Seismic study of multi storey building with and without floating column carried out and it's effects presented [41]

\section{v. CONCLUSION}

Seismic retrofitting has now become a critical issue. Recent occurrences of earthquakes in various parts of the world have clearly illustrated the importance of restoring seismic deficiency structures. Older structures that have been designed with little to no seismic considerations that poses the greatest danger to most communities. Old buildings are a non-reinforced masonry building (URM) and are not engineered. Its construction is purely traditional and lacks all drawings and uses low-quality mortar concrete. The number of floors is up to 4, except in the basement. The builders of the old URM buildings were the founders themselves, who hired the so-called Master Masons and untrained workers. These structures have no intrinsic earthquake resistance capabilities. Masonry buildings began using horizontal connections and then combined horizontal and vertical links as part of seismic code specifications. General observation for the collapse of old buildings are as follows: If the dead weights of the buildings are heavy, the walls and floors will place excessive heavy loads and their material density will be very high. Poor workmanship also contributes to brittle and sudden cracking of joints or buckling of bracing components etc.:-. Architects built comparatively modern URMs, with focus on offering large, uninterrupted space and comfort to the interior. Using a thumb rule the architect specified the beam and column sizes. Contrary to old URMs, this building age has less bearing walls inside and a partial frame of few simply supported girders attached to a limited number of columns supports the floor weights. With the adoption of the seismic code, the construction of engineered buildings using complete beam-to-column steel frames begins. The beams are typically castellated, one for joists, and two for main girders, side by side. The design of the beam-to-column assembly is normally hinged and the structure depends on bracing to withstand lateral loads. Judging from the workmanship, most details are damaged fillet welds. Bracing with many standards or non-standard setups, such as single or double L or I profiles, is used. Old RC buildings are standard non-ductile structures, and almost all of them lack a shear wall. They used a basic assist with inadequate stirrups. This practice continued until the seismic code, which demanded a ductile 
beam-to-column connection, was adopted. The floors of both the buildings are a jack arch, a joist and a block and recently a composite structure. The floor joists are not tied in the old houses. The use of soft-story in all styles of buildings is very common and has caused many failures. Traditionally, seismic testing and other structural improvements have been planned to ensure life-safety or at least reduce the risk of injuries in the earthquake design. Interest in reducing property damage risks has risen over the last decade, either because of maintenance costs or because of the lack of usage of the house. The cost of the retrofit, often more than $25 \%$ of the value of the building, has also led to interest in the study of the costs and benefits of several retrofit levels (and the resulting differences in expected performance levels). This interest in determining the amount of damage anticipated before or after retrofit has contributed in many countries to the establishment of systematic structures for seismic engineering based on performance. Based on the findings of the building inspection, the budget limitations and the focus on life protection, various styles and amounts of reinforcement should be considered. They are classified in the order of complexity and expense as follows: 1) Stable parapets, infill walls and frame veneers using ties. 2) Minimize the excess dead weight of the structure by removing the original heavy material and adding the lighter ones. 3) Strengthen the connections. 4) Add bracing 5)Reinforce frame members or incorporate additional structural elements or ties to URM buildings. 6) Add shear walls to it. 7) In both situations, review the foundation and, if necessary, reinforce it. Reducing the dead weight of old structures is rather satisfying, since it requires low-cost labour, and at times this activity alone will remove or decrease the need or amount of reinforcement. Strengthening approaches used by industry, hospitals, old buildings or modern mid-to high-rise buildings are 1) Active management. 2) The use of carbon fibre 3) Unbonded brace 4) Viscous brace (with viscous content inside) 5) F-Elasto-Plastic dissipation of high ductility content. 6) Shear wall with an effect of energy dissipation (sandwich). 7) Base isolation (high damping rubber, lead core rubber bearing). 8) Lead extrusion damper. 9) Friction and pendulum. Such approaches may not be affordable for small residential or industrial buildings.

\section{Future Work}

Guidelines and recommendations for construction can be made more widely accessible to allow quicker and more efficient use of FRP as seismic material. Despite substantial research on their structural mechanism and durability, there is still a great deal of concern about potential premature loss due to debonding, especially in areas of combined flexural and shear stress. Further study is needed to resolve concerns related to the dynamics, design, and durability of FRP retrofitted concrete and steel structures in order to allow effective use of FRP composites in seismic retrofit applications. An improved understanding of the structural behaviour of the FRP systems and their failure mechanisms, which are often brittle in nature by experimental and numerical simulation, is required. The effect of cyclic and fatigue loading on the improved efficiency of the FRP members must be described and accounted for in the design process. Manuals of design and codes of conduct should be revised to take care of these problems. Based workers should be adequately equipped to ensure successful seismic use of FRP materials for retrofit and recovery purposes. However, a proper and accurate evaluation of the seismic stability and existing condition of the structure is necessary before any seismic retrofit approach is applied to a damaged or deficient structure. Indeed, several of the studies analysed offer only a summary of the overall activity, i.e. storey shear versus storey drift, although a thorough explanation of the order in which various reaction milestones, such as transverse reinforcement and diagonal concrete strut crushing occur, is not always given. The retrofit schemes suggested in the literature require various degrees of labour-intensive and artful descriptions. In comparison, both of these systems were tested on isolated beam-column sub-assemblies with no floor members, i.e. transverse beams and floor slabs. This limits the extent of their applicability and thus delays their implementation in practice. In the other hand, most of the experiments were done on exterior joints. However, corner joints can reflect more critical conditions in building frames due to biaxial seismic loading. Further studies, with special focus on these elements, are highly advised.

\section{Recommendations for Further Research}

- The response of joints should be studied in greater depth because that is where the greatest uncertainties lie. The outer curved bars are particularly vulnerable. The exterior curved bars are especially vulnerable. Experimental and empirical approaches can be used. In order to direct the work, a number of details provided in the 
actual joints should first be identified. The measured strain concentrations at the ends of the jacket should be experimentally tested.

- Evaluation of torsional strength and stability of older beams including non-ductile details should be done. A similar assessment of the combined effects of shear and torsion should also be carried out.

- Member stiffness values used for various degrees of seismic hazard should be defined

- Practical modelling methods, including floor, column, joint and in particular, soil foundation structure interface models, should be built that are useful over a wide variety of current bridge structures and capture the system's dynamic response properly.

\section{REFERENCES}

[1] Ye Lieping et al. "Failure mechanism and its control of building structures under earthquakes based on structural system concept", Journal of Earthquake and Tsunami, Vol 3 , No 4 , 2009, pp: 249-259 DOI: $10.1142 / \mathrm{S} 1793431109000627$

[2] Denis Mitchell et al. "Lessons from the 1985 Mexican earthquake" , Cen. J. Civ. Eng. Vol 13, 1986.pp:535-557.DOI:https://doi.org/10.1139/186-081

[3] Denis Mitchel et al. "Performance of bridges in the 1989 Loma Prieta earthquake - lessons for Canadian designers", Can. J. Civ. Eng. Vol 18, 1991,pp: 711-734.DOI: 10.1139/191-085

[4] Denis Mitchell et al. "Damage to concrete structures due to the 1994 Northridge earthquake", Can. J. Civ. Eng.Vol22,1995,pp:361-377. DOI:https://doi.org/10.113 9/195-047

[5] Murat Saatcioglu et al. "The August 17, 1999, Kocaeli (Turkey) earthquake - damage to structures" Can. J. Civ. Eng. Vol 28,2001,pp: 715-737.DOI:https://doi.org/10.1139/101-043

[6] Minakshi V. Vaghani et al. "Advanced Retrofitting Techniques for RC Building: A State of an Art Review:, International Journal of Current Engineering and Technology,Vol 4, No.2, Apr 2014

[7] Komal Bedi "Study on Various Methods and Techniques of Retrofitting”, International Journal of Engineering Research \& Technology, Vol. 2, No 9, Sep 2013

[8] Jalil Shafaei et al. "Seismic retrofit of external RC beam-column joints by joint enlargement using prestressed steel angles", Engineering Structures Vol 81,2014pp:265-288.http://dx.doi.org/10.1016/j.engstruc t.2014.10.006

[9] G E Thermou et al. "Seismic retrofit schemes for RC structures and local-global consequences", Prog. Struct.EngngMater,Vo18,2006,pp:1-15.DOI: 10.1002/pse.2 08

[10] C. Del Vecchio et al. "Seismic Retrofit of Real Beam-Column Joints Using Fiber-Reinforced Cement Composites” , J. Struct. Eng. Vol 144, No5, 2018,DOI: 10.1061/ (ASCE) ST.1943-541X.000199.

[11] Abdelhak Bousselham " State of Research on Seismic Retrofit of RC BeamColumn Joints with Externally Bonded FRP" Journal of Composites for Construction,Vol.14,No.1,Feb1,2010.DOI:10.1061/(ASCE) CC.1943-5614.0000049
[12] Costas P. Antonopoulos et al. "Experimental Investigation of FRP-Strengthened RC Beam-Column Joints" , Journal of Composites for Construction, Vol. 7, No. 1, February 2003, DOI: 10.1061/(ASCE) 1090-0268(2003)7:1(39)

[13] Chris P. Pantelides, "Seismic Rehabilitation of Reinforced Concrete Frame Interior Beam-Column Joints with FRP Composites" J.Compos.Constr,Vol12,2008,pp:435-445.DOI:10.1061/(A SCE) 1090-0268(2008) 12:4(435)

[14] Halil Sezen, "Repair and Strengthening of Reinforced Concrete Beam-Column Joints with Fiber-Reinforced Polymer Composites"

Compos. Constr,Vol16,2012,pp:499-506,DOI:10.1061/(AS CE)CC.1943-5614.0000290

[15] Ciro Del Vecchio et al. "Experimental Investigation of Exterior RC Beam-Column Joints Retrofitted with FRP Systems", J. Compos. Constr. Vol 18, No4, 2014, pp:1-13.DOI:10.1061/(ASCE)CC. 1943-5614.0000459.

[16] Bing $\mathrm{Li}$ et al. "Seismic Performance of Strengthened Reinforced Concrete Beam-Column Joints Using FRP Composites" Journal of Structural Engineering, Vol. 135, No. $10, \quad$ October $1, \quad 2009$. DOI: 10.1061/(ASCE)0733-9445(2009)135:10(1177)

[17] Gao Ma,Hui Li et al. "Experimental Study of the Seismic Behavior of an Earthquake-Damaged Reinforced Concrete Frame Structure Retrofitted with Basalt Fiber-Reinforced Polymer" Journal of Composites for Construction, Vol. 17, No. $1, \quad$ Feb 9,2014.DOI:10.1061/(ASCE)CC.1943-5614.0000413

[18] Umut Akguzel et al. "Effects of Variation of Axial Load and Bidirectional Loading on Seismic Performance of GFRP Retrofitted Reinforced Concrete Exterior Beam-ColumnJoints",

J.Compos.Constr,Vol14,2010,pp:94-104.DOI:10.1061/(AS CE) 1090-0268(2010) 14:1(94)

[19] Stefano Pampanin et al. egy for Existing Reinforced Concrete Frame Systems Using Fiber-Reinforced Polymer Composites", J. Compos.Constr, Vol1 1,2007,pp:211-226.DOI:10.1061/(ASCE) 1090-0268(2 007) $11: 2(211)$

[20] Amir Mirmiran et al. "Behavior Of Concrete Columns Confined By Fiber Composites", J. Struct. Eng, Vol 123,No5,1997,pp:583-590.DOI:10.1061/(asce)0733-9445( 1997)123:5(583)

[21] Gia Toai Truong et al. "Seismic Performance of Exterior RC Beam-Column Joints Retrofitted using Various Retrofit Solutions" International Journal of Concrete Structures and Materials, Vol.11, No.3, September2017,pp:415-433,DOI:10.1007/s40069-017-02 03-x

[22] A. Ghobarah et al. "Seismic Rehabilitation Of Beam-Column Joints Using FRP Laminates" Journal of Earthquake Engineering, Vol. 5, No. 1,2001.pp:113-129.DOI:https://doi.org/10.1080/136324 60109350388

[23] Idris Bedirhanoglu et al. "Precast fiber reinforced cementitious composites for seismic retrofit of deficient RC joints-A pilot study" EngineeringStructures,Vol52,Feb2013,pp:192-206,DOI:htt ps://doi.org/10.1016/j.engstruct.2013.02.020

[24] Xiuling Li et al. " Cyclic behaviour of damaged reinforced concrete columns repaired with high perdormance fiber reinforced cementitious composite" J.Engineering Strutures, $\quad$ Vol 136 ,Jan2017,DOI:https://doi.org/10.1016/j.engstruct.2017. 01.015 
[25] Alexander G. Tsonos. "Effectiveness of CFRP-jackets and $\mathrm{RC}$-jackets in post-earthquake and pre-earthquake retrofitting of beam-column sub assemblages." Engineering Structures, Vol 30,2008,pp:777-793,DOI:http://dx.doi.org/10.1016/j.en gstruct.2007.05.008

[26] Alireza Zabihi et al. "Seismic retrofit of exterior RC beam-column joint using diagonal haunch. Engineering Structures, Volume 174, No 1 , Nov 2018,pp:753-767,DOI:https://doi.org/10.1016/j.engstruc t.2018.07.100

[27] C. Beschi et al. "Corner Beam-Column Joints Seismic Retrofitting With High Performance Fiber-Reinforced Concrete Jacketing", 15 WCEE, LISBOA , 2012

[28] J. Premalatha et al. "Seismic Retrofitting of Beam-Column Joints in RCC Buildings Using Jacketing Techniques Along With Cross Bars, International Journal of Innovative Technology and Exploring Engineering", Vol 8 ,No: 2S Dec 2018,pp:324-326

[29] Maria Teresa De Risi et al. "Light FRP Strengthening of Poorly Detailed Reinforced Concrete Exterior Beam-Column Joints", J. Compos. Constr. Vol 24,No 3,2020.DOI:10.1061/(ASCE)CC.1943-5614.0001022

[30] A. Torabi et al. "Seismic Repair and Retrofit of RC Beam-Column Joints Using Stiffened Steel Plates" . Iranian Journal of Science and Technology, Transactions of Civil Engineering Vol 41,2017, pp: 13-26. DOI $10.1007 / \mathrm{s} 40996-016-0027-y$

[31] Yousef A. Al-Salloum et al. "Seismic Response of Interior RC Beam-Column Joints Upgraded with FRP Sheets. I: Experimental Study". Journal of Composites for Construction, Vol. 11, No. 6 December 2007, pp: 575-589. DOI: 10.1061/ (ASCE) 1090-0268(2007) 11:6(575)

[32] Yousef A. Al-Salloum et al, "Seismic Behavior of As-Built, ACI-Complying, and CFRP-Repaired Exterior RC Beam-Column Joints". Journal of Composites for Construction, Vol. 15, No 4, August 2011, pp:522-534.DOI:10.1061/ $\quad$ (ASCE) CC. $1943-5614.0000186$.

[33] A.Dalalbashi et al. "Plastic hinge relocation in RC joints as an alternative method of retrofitting using FRP"CompositeStructures, Vo194, No8, July2012,pp:2433-2439DOI:10.1016/j.compstruct.2012.0 2.016.

[34] Thendral sundararasan et al. , "Seismic Retrofitting Schemes For Rc- Structures By Frp Materials" International Journal of Pure and Applied Mathematics, Vol 119, No. 12 , 2018, pp:9687-9694

[35] Chris G. Karayannis et al. "Strengthening and rehabilitation of RC beam-column joints using carbon-FRP jacketing and epoxy resin injection" , Earthquake Engng Struct. Dyn, Vol 37, 2008, pp: 769-790. DOI: $10.1002 /$ eqe. 785

[36] Vui Van Cao et al. "Damage-Based Seismic Retrofitting Approach for Nonductile Reinforced Concrete Structures Using FRP Composite Wraps", Hindawi Advances in Civil Engineering

,Vol2020,pp:1-21.DOI:https://doi.org/10.1155/2020/756 4684

[37] Alper Ilki et al. "Seismic Retrofit of Brittle and Low Strength RC Columns using Fiber Reinforced Polymer and Cementitious Composites" , Advances in Structural Engineering, Vol. 12 ,No. 3 , 2009, pp:325-347, DOI: $10.1260 / 136943309788708356$.

[38] Mahmoud R. Maheri et al. "Seismic Performance Of Rc Frames Retrofitted By Frp At Joints ", 15 WCEE, LISBOA, 2012
[39] Reyes Garcia et al. "Seismic behaviour of deficient RC frames strengthened with CFRP composites",EngineeringStructures,Vol32,2010,pp:3075-3 08.DOI:10.1016/j.engstruct.2010.05.026

[40] T. El-Amoury et al. " Seismic rehabilitation of beam-column joint using GFRP sheets" , EngineeringStructures,Vol24,2002,pp:1397-1407,DOI: 10. 1016/S0141-0296(02)00081-0

[41] Sreadha A R, C.Pany. "Seismic Study of Multistorey Building using Floating Column ", International Journal of Emerging Science and Engineering, Vol 6, No 9 ,April2020,DOI: 10.35940/ijese.G2334.046920

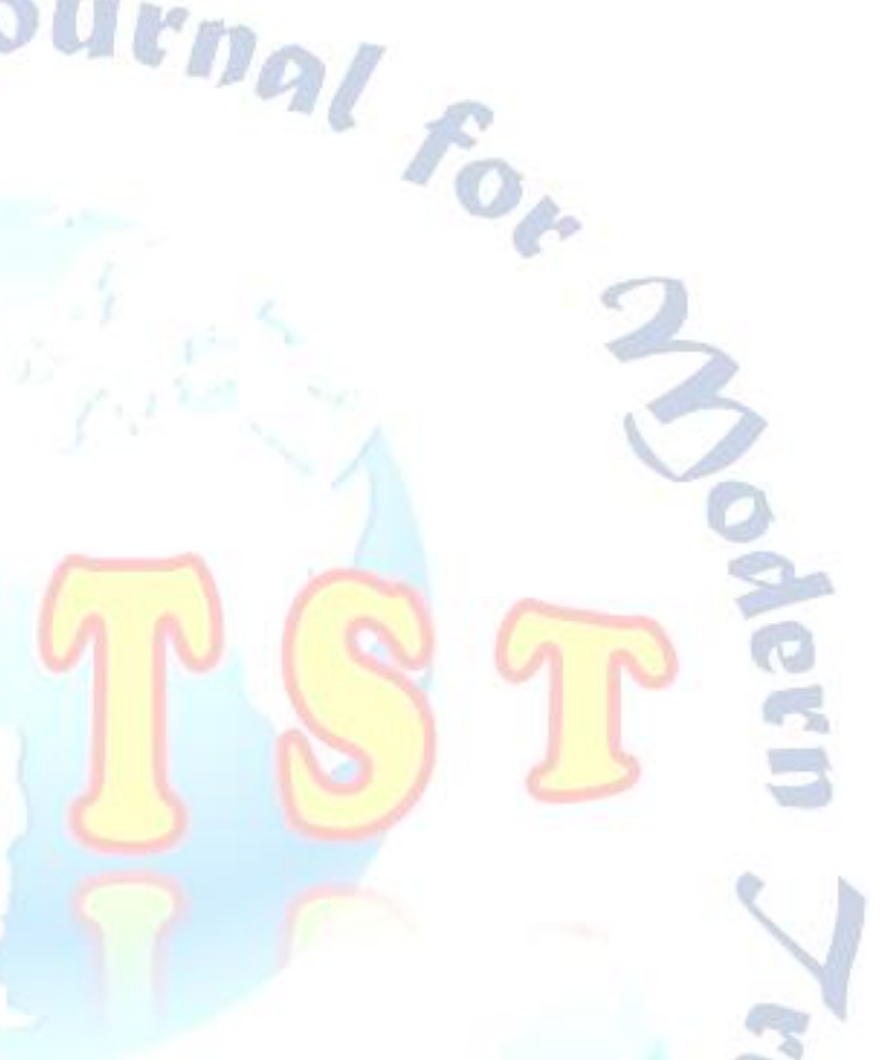

